\title{
Comment on "Excessive Sodium Bicarbonate Infusion May Result in Osmotic Demyelination Syndrome During Treatment of Diabetic Ketoacidosis: A Case Report" by Hsieh et al.
}

\author{
Luigi Mario Castello (D) - Marco Baldrighi · Francesco Gavelli • \\ Gian Carlo Avanzi
}

Received: March 13, 2019 / Published online: July 1, 2019

(C) The Author(s) 2019

Keywords: Diabetic ketoacidosis; DKA; HHS; Hyperosmolar hyperglycemic state; Hyponatremia; ODS; Osmotic demyelination syndrome; Sodium correction

Dear Editor,

We read with great interest the case report recently published in Diabetes Therapy by Hsieh et al. [1], describing a paradigmatic case of diabetic ketoacidosis (DKA) complicated by osmotic demyelination syndrome (ODS). The initial estimate was based on a plasma sodium concentration $\left(P_{\mathrm{Na}}\right)$ correction factor of $1.6 \mathrm{mEq} / \mathrm{L}$ every $100 \mathrm{mg} / \mathrm{dL}$ increase in plasmatic glucose above $100 \mathrm{mg} / \mathrm{dL}$, but more recent evidence supports the use of higher correction factors (up to $4 \mathrm{mEq} / \mathrm{L}$ ) [2]. This underestimation could be partially responsible for a liberal administration of sodium bicarbonate and hypertonic solutions during fluid therapy that led, despite the absence of hyponatremia, to an overly rapid $P_{\mathrm{Na}}$

Enhanced Digital Features To view enhanced digital features for this article go to https://doi.org/10.6084/ m9.figshare.8294681.

L. M. Castello $(\bowtie) \cdot$ M. Baldrighi · F. Gavelli · G. C. Avanzi

Translational Medicine Department, Università del Piemonte Orientale, Via Solaroli, Novara, Italy e-mail: luigi.castello@med.uniupo.it increase and to a fall in plasma osmolality $\left(P_{\text {osm }}\right)$ and, eventually, to ODS.

Although we find the possible correlation between ODS and hypokalemia mentioned by the authors [1] very fascinating, we would like to emphasize the importance of proper management of DKA and hyperglycemic hyperosmolar state (HHS), with a focus on the fluctuations of $P_{\mathrm{osm}}$ and $P_{\mathrm{Na}}$. In our previous works, we set up several mathematical models that allowed us to develop a quantitative approach for the treatment of HHS with the aim of limiting the risk of harmful complications, notably ODS [3, 4]. Recently we proposed a "pragmatic approach" that, in our opinion, could represent a valuable tool in treating HHS patients [5]. Our method is based on a simple algorithm that provides the $P_{\mathrm{Na}}$ expected on the basis of the water shift caused by hyperglycemia $\left(P_{\mathrm{NaG}}\right)$; the difference between the $P_{\mathrm{NaG}}$ and the measured $P_{\mathrm{Na}}$ allows one to stratify patients into three groups: exclusive water shift, sodium deficit greater than water losses, and absolute water deficit. Further formulas allowed us to quantify the alteration. These data are useful in determining the appropriate treatment and, in our opinion, a therapeutic approach based on accurate quantitative estimate of water and solute imbalances should always be recommended since it represents the most reliable strategy to prevent ODS. 


\section{ACKNOWLEDGEMENTS}

Funding. No funding or sponsorship was received for this study or publication of this article.

Authorship. All named authors meet the International Committee of Medical Journal Editors (ICMJE) criteria for authorship for this article, contributed to this manuscript, take responsibility for the integrity of the work as a whole, and have given their approval for this version to be published.

Disclosures. The authors Luigi Mario Castello, Marco Baldrighi, Francesco Gavelli, and Gian Carlo Avanzi have nothing to disclose.

Compliance with Ethics Guidelines. This letter is a response to a previously published article and does not contain any studies with human participants or animals performed by any of the authors.

Open Access. This article is distributed under the terms of the Creative Commons Attribution-NonCommercial 4.0 International License (http://creativecommons.org/licenses/ by-nc/4.0/), which permits any noncommercial use, distribution, and reproduction in any medium, provided you give appropriate credit to the original author(s) and the source, provide a link to the Creative Commons license, and indicate if changes were made.

\section{REFERENCES}

1. Hsieh H-C, Wu S-H, Chiu C-C, Ko K-C. Excessive sodium bicarbonate infusion may result in osmotic demyelination syndrome during treatment of diabetic ketoacidosis: a case report. Diabetes Ther. 2019;10:765-71.

2. Spasovski G, Vanholder R, Allolio B, et al. Clinical practice guideline on diagnosis and treatment of hyponatraemia. Nephrol Dial Transpl. 2014;29(Suppl 2):i1-39.

3. Bartoli E, Sainaghi PP, Bergamasco L, Castello L. Computation of the excess glucose and $\mathrm{Na}$ deficit of hypo-osmolar hyponatremic hyperglycaemia. Acta Diabetol. 2010;47:147-54.

4. Bartoli E, Sainaghi PP, Bergamasco L, Castello L. Hyperosmolar coma due to exclusive glucose accumulation: recognition and computations. Nephrology (Carlton). 2009;14:338-44.

5. Baldrighi M, Sainaghi PP, Bellan M, Bartoli E, Castello LM. Hyperglycemic hyperosmolar state: a pragmatic approach to properly manage sodium derangements. Curr Diabetes Rev. 2018;14:534-41. 